\title{
The drivers influencing the relationship between sales representatives and customers and the impact this relationship has on sales volume within Coca-Cola's Western Cape region
}

\author{
F.J. Herbst* \\ University of Stellenbosch Business School, PO Box 610, Bellville 7535, \\ Republic of South Africa \\ fjh@usb.ac.za \\ C.L. Forrest \\ Franchise Manager Forbes Group (Western Cape), \\ Coca-Cola South Africa (Pty) Ltd \\ cforrest@afr ko.com \\ Received March 2008
}

\begin{abstract}
Companies within the FMCG sector are continually trying to create value from their brands by increasing their margins and/or selling more of their products. Taking cost out of the value chain gives the company a competitive advantage, but this advantage is short lived as competitors also reduce costs. Differentiating a product through enhanced features and benefits also provides a competitive advantage, but is also subject to imitation by rivals. As competition increases, companies are looking for new avenues to differentiate themselves. Relationship marketing has, as a result, increased its prevalence as a competitive tool to provide that point of difference.
\end{abstract}

This research investigated the factors that influence the relationships between a Coca-Cola sales representative and his/her customers within the Cape Town region.

\begin{abstract}
This article was developed after studying literature as it pertained to customer relationship marketing. From the literature the foundation blocks in developing buyer-seller relationships were studied. The research methodology tested the impact of certain factors on the ability to build a relationship between buyer and seller and then tested the validity of those answers using underlying determinants of a relationship. These determinants included the ability to communicate, the ability to trust, the degree of loyalty and the ability to influence a customer.
\end{abstract}

\begin{abstract}
The response to the questionnaires was extremely high (over 95\%) and provided for a robust evaluation of data. The research showed that there was a positive correlation between the profile of a sales representative and a customer. It is easier for a sales representative to build a relationship with a customer who is a similar age. It is however easier for the sales representative to influence a younger customer. Gender plays no role in a sales representative's ability to build a relationship. With respect to education, a stronger relationship exists between a customer and sales representative of a similar education. Again it is easier for a representative to influence a customer who has a lower level of education. Race does have an impact on the ability to build relationships. The research showed that an African sales representative should service an African customer. There was a positive link between matching sales representatives and customers who come from similar areas and have the same religion. There was no correlation between the degree of the relationship that a Coca-Cola sales representative in the Western Cape region has with a customer and the sales growth within the outlets. This final conclusion must be read in the context of the relative high market share that the Coca-Cola Company has in the Western Cape.
\end{abstract}

*To whom all correspondence should be addressed.

\section{Introduction}

It is suggested that positive relationships have an impact on the sales representative's ability to influence the store owner to activate certain in-store drivers which will increase the sales volume of products through an outlet. In-store drivers have been defined as the availability of a product through listing, the amount of forward share allocated to the product and the price of the product. If the profile of a sales representative relative to that of a customer, has an impact on the strength of the relationship, companies could "match" sales representatives to customers based on their respective profiles. This "matching” would have a positive benefit for the sales representative and his/her company.

Understanding what factors can improve or inhibit a relationship provides important insights into how management can influence a competitive advantage in customer relationship marketing. 


\section{Literature review}

\section{Defining a relationship, relationship marketing and customer relationship marketing}

A relationship is composed of a series of episodes between dyadic parties over time Buttle (2005:13). Marketing in relational terms means to establish, maintain and enhance relationships with customers and other partners, at a profit so that the objectives of parties involved are met. This is achieved by mutual exchange (Grönroos, 1997:327).

Relationship marketing (RM) is used to describe the philosophy and orientation towards customer retention and is an important trend in marketing. It is based on the organisation's effort to develop long-term, mutual beneficial links with customers. Du Plessis, Jooste and Strydom (2001: 90) posit that a CRM philosophy is based on the concept of building long-term quality relationships with customers who will provide value to the organisation. The relationship marketing perspective is based on the notion that on top of value of products and/or services that are exchanged, the existence of a relationship between two parties creates additional value for the customer and also for the suppliers or service provider (Grönroos, 2004: 99).

Customer relationship marketing (CRM) is regarded as the practical implementation of relationship marketing and is the core business strategy that integrates internal processes and functions, and external networks, to create and deliver value to targeted customers at a profit. It is grounded on high-quality customer data and enabled IT (Buttle, 2005:43). The general aim of any CRM strategy is to develop more profitable relationships with customers. Some organisations do this by taking cost out of the relationship and others do this by increasing the revenue earned from a customer relationship (Buttle, 2005:40).

Payne (2006: 111) highlights the fact that customers value relationships with trusted suppliers. As a result of the association of value with relationships it is important for suppliers to put effort into maintaining and constantly improving these relationships.

\section{Stages in relationship building}

Boles, Hiram, Barksdale and Johnson (1997: 253) identified a five-stage relationship evolution process. These stages are pre-relationship stage, early stage, development stage, long term stage and the final stage. Within these stages, Boles et al. (1997: 253) identified certain categories of perceptions that influence the future development of a relationship. Ford (1982: 92-103) identifies one of these categories as being the distance because of differences in social, geographic and cultural backgrounds. In the early stage of development Dwyer, Schurr and Oh (1987:11-27) called out the need to reduce the social distance between buyer and seller if a long-term sustainable relationship is to develop. The sales person is the point of contact between the selling organisation and the company. It therefore becomes important to understand what factors will influence the strength of that relationship and what the entry-level factors are that need to be considered prior to this stage. The relationship gap between a buyer and a seller closes as knowledge of each firm becomes known and as personal relationships develop between individuals (Moorman, Zaltman \& Deshpande, 1992: 23-34).

There are different stages in building a relationship. Such stages can be represented in the loyalty ladder depicted in Figure 1.

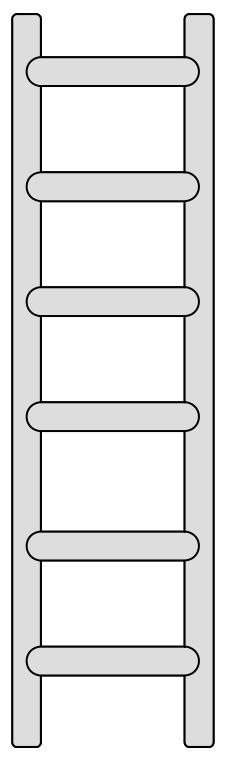

\section{Partner}

Someone who is a business partner; both parties seek an on-going profitable relationship

\section{Advocate}

Someone who actively recommends you to others, who does your marketing for you

\section{Supporter}

Someone who likes your organisation but only supports you

\section{Client}

Repeat customer, but may be negative or at best neutral towards your organisation

\section{Buyer}

Someone who has done business

once with your organisation

\section{Prospect}

Someone who has yet to do business with the organisation

Figure 1: The customer ladder of loyalty

Source: Adapted from Payne (2006:112)

The ultimate goal is to reach the top of the ladder and develop a partner relationship, but Payne (2006: 112) calls out the need to understand that it becomes more difficult to build a relationship the higher one climbs up the ladder.

\section{Key characteristics of relationships}

Satisfaction, trust and commitment are the core values in relationship marketing (Little \& Marandi, 2003:43). According Ulaga and Eggert (2006: 313) satisfaction is a strong predictor for behavioural outcomes such as repurchasing intentions, word-of-mouth or loyalty. Trust is one parties belief that its needs will be fulfilled in the future by actions taken by the other party and according to the commitment-trust theory by Morgan and Hunt (1994:20 38) trust is the key mediating variable that is central to any relational exchange.

Commitment is defined by as an enduring desire to maintain a valued relationship and committed relationship partners are unlikely to switch even if a competing supplier outperforms the incumbents value offer (Ulaga \& Eggert, 2006: 315). Morgan and Hunt (1994:23) posit that parties identify commitment among exchange partners as a key to achieving valuable outcomes for themselves and they endeavour to develop and maintain this precious attribute in their relationship. Commitment is a motivational force driving the individual towards an action or behaviour and in marketing, commitment to a relationship is widely accepted as a behavioural measure of performance (Bhagat \& Williams, 2008:16). 
This study examines the impact that age, gender, education and culture have on the ability of a sales representative to build a relationship with a customer. Culture is broken down into four categories and these categories examined race, language, religion and area of residence of a sales representative relative to a customer and the impact these attributes have on the ability to build a relationship.

\section{The research problem}

A company can produce a product, create the demand for it, but fail by not having that product available for the shopper to purchase. The focus of this article is to examine the factors which influence the relationship between a sales representative and a customer, and the impact of the relationship on the sales within an outlet. A supplier can determine who to send to a customer. If a particular profile of sales representative increases the sales volume within an outlet it would be in the interests of the supplier to ensure that the "right" person with the most appropriate profile is sent to that customer.

The study was developed to solve the following four research problems:

- The first related to whether there is a relationship between the profile of a sales representative and that of the customer (linked to hypotheses 1 - 35).

- $\quad$ The second to determine whether the strength of a relationship will influence the ability to affect the instore drivers (linked to hypotheses 36 - 38).

- $\quad$ The third to determine whether these in-store drivers affect sales volume (linked to hypotheses 39 -40).

- The fourth to determine if there is a correlation between the strength of the relationship that a sales representative has with a customer and the sales volume growth from that customer (linked to hypothesis 41).

The profile of a sales representative relative to the customer was defined by using the determinants of gender age, education and culture.

\section{The research objective}

The primary research objective was to determine if a positive relationship has an impact on the in-store drivers and ultimately the sales volume in an outlet.

\section{Hypotheses}

The hypotheses below were formulated and linked to the four research problems.

\section{Hypotheses linked to research problem one}

Hypotheses were formulated to test the ability to build a relationship $\left(\mathrm{H}_{1}-\mathrm{H}_{7}\right)$, the ability to communicate with a customer $\left(\mathrm{H}_{8}-\mathrm{H}_{14}\right)$, the ability of trust a customer $\left(\mathrm{H}_{15}-\right.$
$\mathrm{H}_{21}$ ), the degree of loyalty $\left(\mathrm{H}_{22}-\mathrm{H}_{28}\right)$ and the ability to influence a customer $\left(\mathrm{H}_{29}-\mathrm{H}_{35}\right)$.

\section{Hypotheses linked to research problem two}

Hypotheses 36 - 38 were formulated to test the relationship between the strength of a relationship and the impact this relationship has on the in-store drivers. It was assumed that there will be a positive relationship between the strength of the customer and sales representatives' relationship and the ability of the sales representative to affect the listing of products, the placement of cooling equipment and displays and the compliance to recommended selling prices.

$\mathbf{H}_{36}$ : The stronger the relationship a sales representative has with a customer the easier it is to list a new product.

$\mathbf{H}_{37}$ : The stronger the relationship that a sales representative has with a customer the easier it is to get a display built in the outlet.

$\mathbf{H}_{\mathbf{3 8}}$ : The stronger the relationship that a sales representative has with a customer the easier it is to get price compliance in an outlet.

\section{Hypotheses linked to research problem three}

Hypotheses 39 - 40 were formulated to test the sales representative's belief that the strength of the relationship that he or she has with the customer will influence his or her ability to list, increase forward inventory and get price compliance within an outlet.

$\mathbf{H}_{39}$ : If you increase the amount of forward share in an outlet by building displays and increasing the points of interruption you will increase the volume in that outlet.

$\mathbf{H}_{40}$ : If you get price compliance in an outlet you will increase the volume within that outlet.

\section{Hypothesis linked to research problem four}

Hypothesis 41 was formulated to test the strength of the relationship between a sales representative and a customer and actual volume growth in the outlet.

$\mathbf{H}_{\mathbf{4 1}}$ : A sales representative who has a strong relationship with customers has a higher actual sales volume growth in his/her outlets.

\section{Research methodology}

Deductive research was used and the data was gathered through two separate surveys.

\section{Questionnaire design}

Two questionnaires were used to gather information. The data variables in both questionnaires, with the exception of the personal demographic questions, were opinion based. Ordinal scale questions were used to gather the opinion data. 
Nominal scales/category questions were used to gather the respondent's demographic data. A five point Likert scale was used in the first questionnaire and a six point Likert scale in the second. The second questionnaire was linked to the respondents of the first questionnaire and a six point scale was use to prevent the respondents from choosing the mean as a "safe" option as a result of evidence of this selection in answers from the first questionnaire. The scale of the second questionnaire was ranked from one to six while it should have been ranked from six to one. The value of the numbers in the evaluation of the data had to be reversed in order to measure whether a positive correlation existed.

\section{Sampling and data gathering}

The research was conducted within Cape Town and surrounding areas including Paarl Somerset West and Stellenbosch. The research involved the gathering of information from the sales representatives and sales managers of Coca-Cola (Peninsular Beverages). Peninsular Beverages has a complement of 65 sales representatives, each servicing an average of 200 customers on a weekly basis. The area serviced by this sales force included four sales areas - Parow, Athlone, Blackheath and Paarl as defined by the local bottling company.

Probability sampling method was used through the application of the random sampling technique and ninety percent of the sales force participated in the data gathering of this survey. Questionnaires were distributed centrally through the general sales managers of each plant. Both questionnaires were handed to the sales representatives through their respective sales managers. Sales representatives were given one week to complete the questionnaires. Questionnaire two was linked to the respondents of the first questionnaire. Primary customer data was drawn for each sales representative who responded to the first questionnaire. From an individual sales route the top 50 customers by sales volume for a 12 month period (May 2006 - May 2007) were identified. From these top 50 customers by sales representative the top and bottom 10 performers with respect to volume growth over the prior year were identified. These 20 customers were placed into a separate list. Using random number generation the top 20 customers were rearranged. The volume contribution and sales growth for each customer were then hidden in the excel document.

\section{Data analysis}

The dataset was tested for normality and resulted in the use of non-parametric statistical techniques such as the Friedman ANOVA for repeated ordinal measures, the Kruskall-Wallis test for comparing several groups/categories and the goodness of fit test to a uniform distribution.

All the data was transferred to an excel spreadsheet. The results from the survey were matched to the volume growth. The data as it related to the strength of the relationship and volume growth was transferred into two columns which were used in the correlation analysis. The Spearman rank correlation coefficient was used to rank the nonparametric data and evaluated the strength of the association between the strength of the relationship and sales growth in an outlet. The p-value was used to measure the significance of this correlation.

\section{Research results}

\section{Response rate}

An amount of 72 sales representatives participated in this study where 65 were current sales representatives and 7 were sales representatives who have recently became sales managers. A 95\% response rate was achieved.

\section{Hypothesis results}

The following hypothesis results are linked to the ability of the sales representatives to build relationships, their ability to communicate, their ability to build trust, their ability to build loyalty and their ability to influence to influence the customer.

\section{The ability to build a relationship $\left(\mathrm{H}_{1}-\mathrm{H}_{7}\right)$}

i. It is easier to build a relationship with a customer who is the same age or younger than the sales representative.

ii. The ability to build a relationship with customers is the same irrespective of gender.

iii. It is easier to build a relationship with a customer who has a similar education to that of the sales representative.

iv. It is not easier for a sales representative to build a relationship with a customer of a similar race. Race plays no role in the ability to build a relationship.

V. It is easier for a sales representative whose home language is English/Afrikaans/Xhosa to build a relationship with a customer whose home language is English/Afrikaans/Xhosa.

vi. It is easier for a sales representative to build a relationship with a customer who lives in a similar area.

vii. It is easier for a sales representative to build a relationship with a customer who has the same religion.

Ability to communicate with a customer $\left(\mathrm{H}_{8}-\mathrm{H}_{14}\right)$

viii. It is easier for a sales representative to communicate with a customer of a similar age.

ix. The ability of a sales representative to communicate with customers is the same irrespective of gender. 
X. It is easier for a sales representative to communicate with a customer with a similar education.

xi. The ability for a sales representative to communicate with customers is the same irrespective of race.

xii. It is easier for a sales representative whose home language is Xhosa to communicate with a customer whose home language is Xhosa.

xiii. It is easier for a sales representative to communicate with a customer who lives in the same area.

xiv. It is easier for a sales representative to communicate with a customer who has the same religion.

The ability of trust a customer $\left(\mathrm{H}_{15}-\mathrm{H}_{21}\right)$

XV. A sales representative has a higher degree of trust with an older customer.

xvi. Gender has no impact on the degree of trust between a sales representative and a customer.

xvii. The level of education of a customer relative to that of a sales representative has no impact on the degree of trust between a sales representative and a customer.

Xviii. A sales representative's degree of trust is the same with a customer irrespective of race.

xix. A sales representative whose home language is English/Afrikaans/Xhosa has a higher degree of trust with a customer whose home language is English/Afrikaans/Xhosa.

Xx. The area of residence of a sales representative relative to a customer has no impact on the degree of trust.

xxi. A sales representative has a higher degree of trust with a customer that has the same religion.

Ability to build loyalty $\left(\mathrm{H}_{22}-\mathrm{H}_{28}\right)$

xxii. A sales representative's gets a higher degree of loyalty from a customer that is older than the sales representative.

xxiii. A sales representative gets a higher degree of loyalty from a customer who is the opposite gender.

xxiv. A sales representative gets a higher degree of loyalty from a customer of a similar level of education.
XXV. An African sales representative gets a higher degree of loyalty from an African customer. A sales representative's degree of loyalty from a coloured customer is the same for all races. A sales representative's degree of loyalty from a white customer is the same for all races. A sales representative's degree of loyalty from an Indian customer is the same for all races.

XXVi. A sales representative's degree of loyalty from a customer who speaks English/Afrikaans/Xhosa is the same for all home language groups.

XXvii. A sales representative gets a higher degree of loyalty from a customer who lives in the same area.

Xxviii. A sales representative gets a higher degree of loyalty from a customer with the same religion.

The ability to influence a customer $\left(\mathrm{H}_{29}-\mathrm{H}_{35}\right)$

Xxix. A sales representative finds it easier to influence a younger customer.

XXX. A sales representative's ability to influence a customer is the same for both genders.

XXxi. A sales representative finds it easier to influence a customer who has a lower level of education relative to his/her level of education.

Xxxii. An African sales representative finds it easier to influence an African customer. A sales representative's ability to influence a coloured/White/Indian customer is the same for all races.

Xxxiii. A sales representative's ability to influence a customer who speaks English/Afrikaans/Xhosa is the same for all home language groups.

XXxiv. It is easier for a sales representative to influence a customer who lives in a similar area to that of the sales representative.

XXXV. A sales representative finds it easier to influence a customer who has the same religion.

Table 1 below depicts the profile of the ultimate sales representative based on the research results above. 
Table 1: The "ultimate” sales representative

\begin{tabular}{|c|c|}
\hline Variables & Qualities \\
\hline Age & Same age and older \\
\hline Gender & Either male or female \\
\hline Education & Same or higher level of education \\
\hline \multirow{2}{*}{ Race } & $\begin{array}{l}\text { African sales representative should service } \\
\text { African customer }\end{array}$ \\
\hline & $\begin{array}{l}\text { Coloured and White should be matched with } \\
\text { Coloured and White }\end{array}$ \\
\hline \multirow{2}{*}{ Language } & $\begin{array}{l}\text { Xhosa sales representative should serve Xhosa } \\
\text { customer }\end{array}$ \\
\hline & $\begin{array}{l}\text { English and Afrikaans sales representative can } \\
\text { service English and Afrikaans customer }\end{array}$ \\
\hline $\begin{array}{l}\text { Area of } \\
\text { residence }\end{array}$ & $\begin{array}{l}\text { Representative should come from similar area to } \\
\text { that of the customer }\end{array}$ \\
\hline Religion & $\begin{array}{l}\text { Representative should have the same religion as } \\
\text { customer }\end{array}$ \\
\hline
\end{tabular}

The variables and qualities depicted in Table 1 provide the necessary context for the interpretation of the results based on the strength of relationships to follow.

\section{Relationship ability to influence in-store drivers}

The next section of the study was related to the impact of the customer relations on the in-store drivers linked to research problem two. Table 2 provides a summary of the hypotheses results as they relate to the impact on relationships.

The individual results on $\mathrm{H}_{36}-\mathrm{H}_{40}$ and the interpretation thereof are discussed below:

$\mathrm{H}_{36}$ : The sales representative believes that there is a positive relationship between the strength of the relationship he/she has with a customer and the ability to list a product in an outlet.

It was observed that 76 percent of respondents strongly agree with the above hypothesis. The mean responses differ with overwhelming evidence. The test has a high degree of significance with a Chi square of 149,378 and a p-value of 0,0000 . Based on this evidence the null hypothesis was rejected in favour of the alternative hypothesis.

It can therefore be concluded that the stronger the relationship between a sales representative and a customer the easier it is for the sales representative to list a new product.
$\mathrm{H}_{37}$ : The sales representative believes that there is a positive relationship between the strength of the relationship he/she has with a customer and the ability to get a display built in the outlet.

It is observed that 70 percent of respondents strongly agree with the above hypothesis. The mean responses differ with overwhelming evidence. The test has a high degree of significance with a Chi square of 23,096 and a p-value of 0,0000 . Based on this evidence the null hypothesis is rejected in favour of the alternative hypothesis.

It can therefore be concluded that the stronger the relationship between a customer and a sales representative the easier it is to get a display built in the outlet.

$\mathrm{H}_{38}$ : The sales representative believes that there is a positive relationship between the strength of the relationship he/she has with a customer and the ability to influence the price that products are sold for in an outlet.

It is observed that 38 percent of respondents strongly agree and 31 percent agree with the above hypothesis. The mean responses differ with overwhelming evidence. The test has a high degree of significance with a Chi square of 32,216 and a p-value of 0,0000 . Based on this evidence the null hypothesis is rejected in favour of the alternative hypothesis.

It can therefore be concluded that the stronger the relationship between a customer and a sales representative the easier it is to get price compliance in an outlet. The ability to influence price is not as strong as that of listing or building a display in an outlet.

The correlation between in-store drivers and sales volume

The next section of the study was related to the correlation between in-store drivers and sales volume linked to research problem three.

$\mathrm{H}_{39}$ : If a sales representative increases the amount of forward share in an outlet there will be an increase in sales volume within that outlet.

It is observed that 62 percent of respondents strongly agree with the above hypothesis. The mean responses differ with overwhelming evidence. The test has a high degree of significance with a Chi square of 94,243 and a p-value of 0,0000 . Based on this evidence the null hypothesis is rejected in favour of the alternative hypothesis. 
Table 2: Impact of relationship

\begin{tabular}{|c|c|c|c|c|}
\hline Hypothesis & $\begin{array}{l}\text { *Frequency on a five } \\
\text { point Likert scale }\end{array}$ & $p$ value & $\begin{array}{c}\text { Chi square } \\
\chi^{2}\end{array}$ & $\begin{array}{c}* * \text { Hypothesis } \\
\text { result }\end{array}$ \\
\hline $\begin{array}{l}\mathrm{H}_{36}: \text { The stronger your relationship with your customer the } \\
\text { easier it is to convince him or her to list a new product }\end{array}$ & $76 \%$ & 0,0000 & 149,378 & Reject \\
\hline $\begin{array}{l}\mathrm{H}_{37} \text { : The stronger the relationship with your customer the } \\
\text { easier it is to get a display built in the outlet }\end{array}$ & $70 \%$ & 0,0000 & 23,096 & Reject \\
\hline $\begin{array}{l}\mathrm{H}_{38}: \text { The stronger the relationship with your customer the } \\
\text { easier it is to get price compliance in an outlet }\end{array}$ & $38 \%$ & 0,0000 & 32,216 & Reject \\
\hline $\begin{array}{l}\mathrm{H}_{39} \text { :If you increase the amount of forward share in an outlet by } \\
\text { building displays and increasing the points of interruption you } \\
\text { will increase the volume in that outlet }\end{array}$ & $62 \%$ & 0,0000 & 94,243 & Reject \\
\hline $\begin{array}{l}\mathrm{H}_{40} \text { : If you get price compliance in an outlet you will increase } \\
\text { the volume within that outlet }\end{array}$ & $61 \%$ & 0,0000 & 87,216 & Reject \\
\hline
\end{tabular}

*Note: $1=$ strongly agree and 5 = strongly disagree.

**Note: $\mathrm{H}_{0}$ : The percentage contribution of answers across the five point Likert scale will all be the same i.e.p1=p2=p3=p4=p5=0.2 (20\%).

It can therefore be concluded that there is a positive relationship between the amount of forward share in an outlet and the sales volume within that outlet.

$\mathrm{H}_{40}$ : If the sales representative gets price compliance in an outlet there will be an increase in sales volume within that outlet.

It is observed that 61 percent of respondents strongly agree with the above hypothesis. The mean responses differ with overwhelming evidence. The test has a high degree of significance with a Chi square of 87,216 and a p-value of 0,0000 . Based on this evidence the null hypothesis is rejected in favour of the alternative hypothesis.

It can therefore be concluded that there is a positive relationship between price compliance and sales volume in an outlet.
The strength of the relationship between a sales representative and a customer and actual volume growth in the outlet

The next section of the study was related to the strength of the relationship between a sales representative and a customer and the actual volume growth in the outlet linked to research problem three.

$\mathrm{H}_{41}$ : A sales representative who has a strong relationship with customers has a higher sales volume growth across his/her outlets.

Figure 2 below illustrates the range of growth from $-100 \%$ to $+100 \%$.

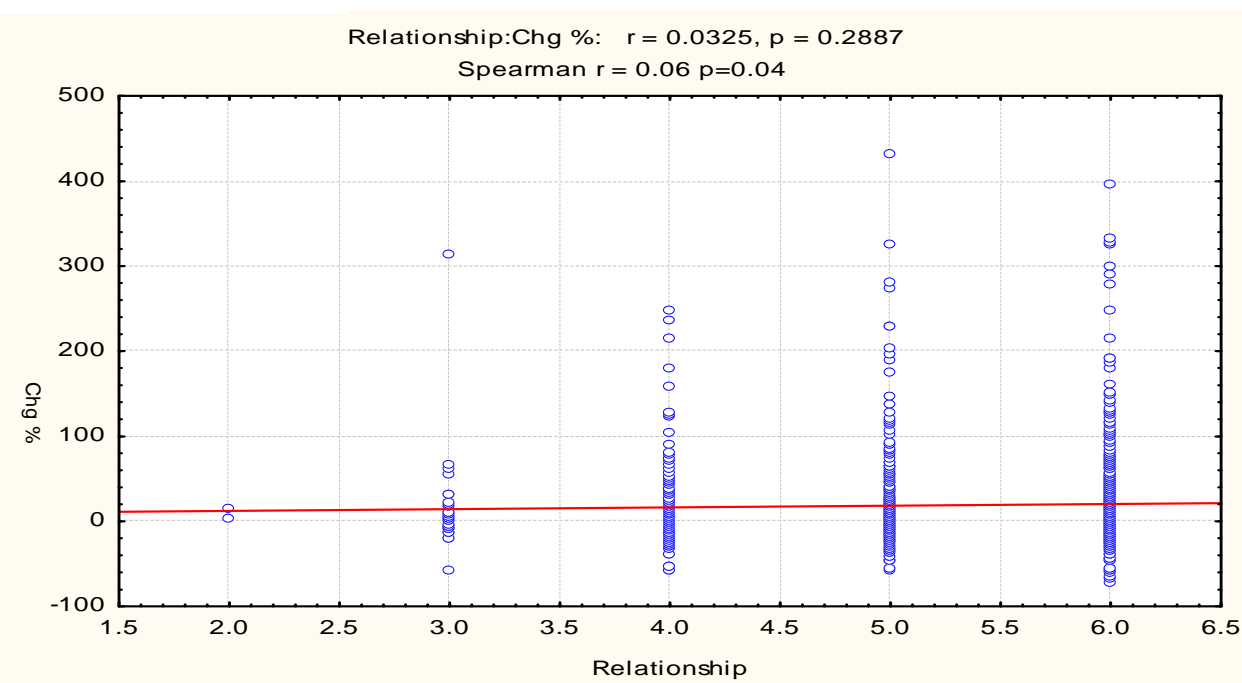

Figure 2: Scatter plot on the range of growth: $-100 \%$ to $+100 \%$ 
In Figure 2 above the outlets included in the analysis had a range of growth between -100 percent and +400 percent. The p-value of 0,04 would indicate that there is a positive correlation between the strength of a customer and sales representative relationship and the positive sales growth within an outlet. The evidence is however weak.

Figure 3 below illustrates the range of growth from $-20 \%$ to $+20 \%$.

In Figure 3 the growth range was limited to a range between -20 percent and +20 percent. This was seen to be more realistic and would eliminate growth that resulted from external variables. The $\mathrm{p}$-value of 0,46 would indicate that that there is no evidence to infer that the alternative hypothesis was true.

It can therefore be concluded that there is no correlation between the degree of the relationship that a Coca-Cola sales representative in the Western Cape region has with a customer and the sales growth within the outlets.

\section{Managerial implications and recommendation to management}

The Coca-Cola sales force with respect to race in the Western Cape is representative of the population. Due to past segregation the sales force live in areas which are to a large degree representative of the customers they serve. There has been a natural alignment of profile between customers and sales representatives. The current strength of the relationship between a sales representative and a customer (outlet) can be regarded as strong, but the following recommendations should be considered:

- African customer whose home language is Xhosa should be serviced by African sales representatives who also have Xhosa as their home language.

- Customers should be matched on the basis of age to sales representatives. A similar age is preferable.

- Better education is an advantage from a sales perspective. It was pointed out that it is easier to influence a customer with a lower level of education. Training and a higher level of intelligence relative to the customer can give the company a sustainable competitive advantage.

- Assigning sales routes which are similar to those where the sales representative live is an advantage.

A data base capturing the profile of customers relative to sales representatives needs to be established. While it is not logistically possible to match everyone, an understanding of the current situation is important. Targets as to what should be achieved or maintained need to be established if the organisation is to become relationship focused. Establishing a current reality picture and a destination are crucial management steps which need to be considered.

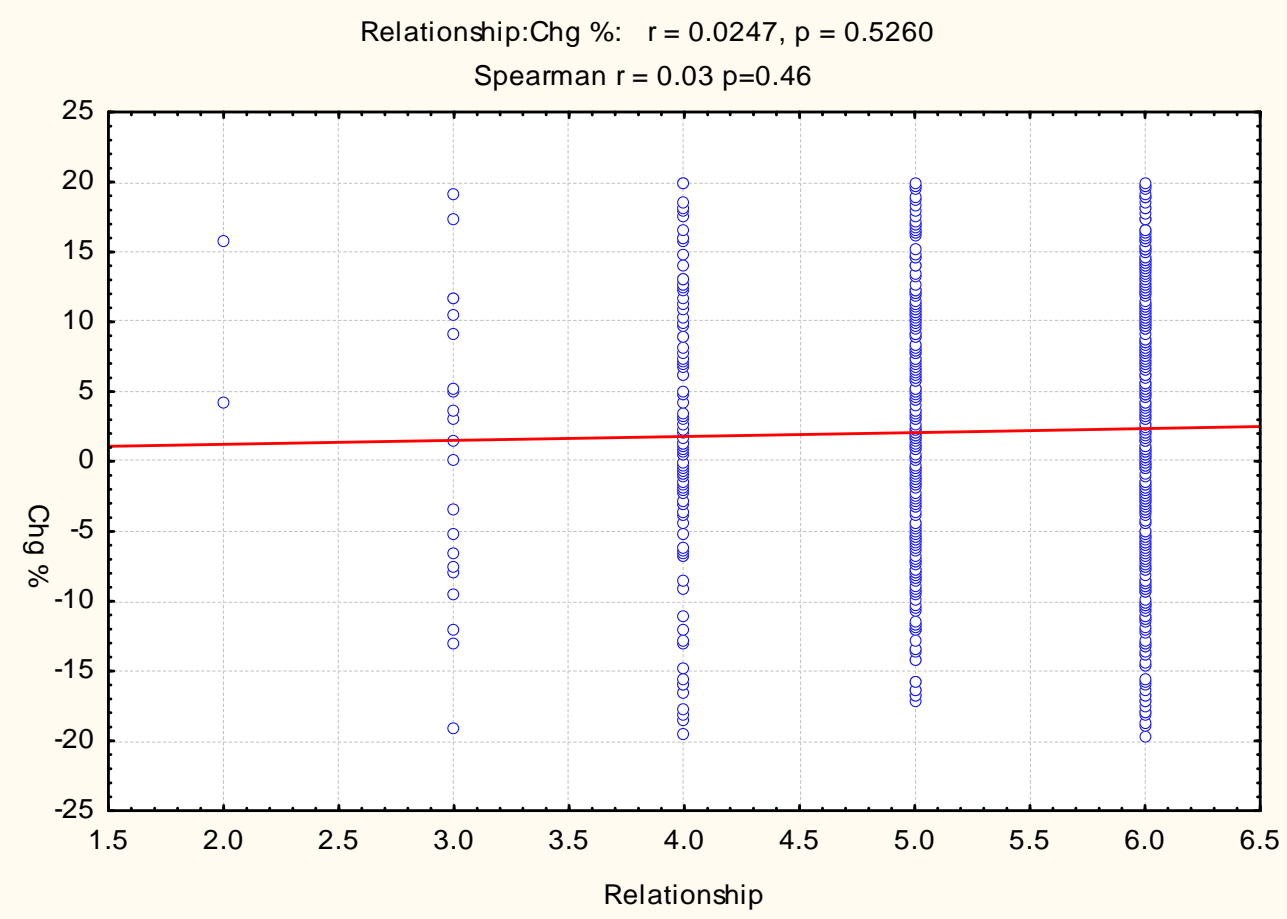

Figure 3: Scatter plot on the range of growth: $-20 \%$ to $+20 \%$ 


\section{Conclusion}

There is significant evidence that the profile of a sales representative does have an impact on his or her ability to build a relationship with a customer and that from a sales representative's perspective there is a link between the relationship and the ability to impact the in-store drivers. Further to this, the sales representatives believe that manipulating the in store drivers will have a positive impact on the sales volume within an outlet. The growth in volume over one year did however not support the idea that a strong relationship would lead to a positive growth in volume. As competition increases relationships will play more of a critical role in selling. It is important to understand the link and develop a process which will give the organisation a competitive advantage for the future.

\section{References}

Bhagat, P.S. \& Williams, J.D. 2008. 'Understanding gender differences in professional service relationships', Journal of Consumer Behaviour, 25 (1):16 - 22.

Boles, J., Hiram, C., Barksdale, J.R. \& Johnson, J. 1997. 'Business relationships: an examination of the effects of buyer-salesperson relationships and willingness to refer and recommend', Journal of Business \& Industrial Marketing, 12(3/4): 253-264.

Buttle, F. 2005. Customer relationship management concepts and tools. Oxford, Butterworth Heinemann.

Du Plessis, P.J., Jooste, C.J. \& Strydom, J.W. 2001. Applied strategic marketing. Sandown: ButterworthHeinemann.

Dwyer, F.R., Schurr, P. H. \& Oh, S. 1987. 'Developing buyer-seller relationships', Journal of Marketing, 51(April): $11-27$.

Ford, D. 1982. 'The development of buyer-seller relationships in industrial markets'. In Hakansson, H. (Ed.). International marketing and purchasing of industrial goods. Chichester: John Wiley \& Sons.

Grönroos, C. 1997. 'From marketing mix to relationship marketing - towards a paradigm shift in marketing', Management Decisions, 35(4): 322-329.

Grönroos, C. 2004. 'The relationship marketing process: communication, interaction, dialogue, value', Journal of Business and Industrial Marketing, 19(2): 99-113.

Little, E. \& Marandi, E. 2003. Relationship marketing management. London, Thomson.

Moorman, C., Zaltman, G. \& Deshpande, R. 1992. 'Relationships between providers and users of market research: The dynamics of trust within and between organizations', Journal of Marketing Research, 29(3): 314328.
Morgan, R.M. \& Hunt, S.D. 1994. 'The commitment-trust theory of relationship marketing', Journal of Marketing, $\mathbf{5 8}$ (3):20 - 38 .

Payne, A. 2006. Handbook of CRM - Achieving excellence in customer management. Burlington: ButterworthHeinemann.

Ulaga, W. \& Eggert, A. 2006. 'Relationship value and relationship quality - Broadening the nomological network of business-to-business relationships', European Journal of Marketing, 40 (3/4):311 - 327. 